\section{Analysis of various factors responsible for hair loss and awareness level in Delhi and the National Capital Region of India}

\author{
Archana Aggarwal, Rakhi Gupta*, \\ Navdha Thukral, Gargi Nandi and Garima Bora \\ Zoology Department, Maitreyi College, University of Delhi, \\ Delhi 110 021, India
}

The aim of this study was to assess the prevalence, causes and awareness about various factors related to hair loss in subjects of Delhi and the National Capital Region of India. A survey-based study was conducted with 380 participants. Total dissolved solids level of water samples used for hair wash was also analysed. Majority of subjects $(96.5 \%)$ were affected with hair loss. High percentage of subjects were unaware about the role of diet $(94 \%)$, iron content $(77.65 \%)$, hormonal level $(89.92 \%)$ and genetic factors $(93.19 \%)$ with respect to hair loss. Persistent, long-term hair loss is an indicator of some disturbance in physiological or environmental factors. Therefore, it is imperative to generate awareness among the population at regular intervals.

Keywords: Genetic factors, hair loss, hormones, iron deficiency, total dissolved solids.

HAIR loss or alopecia is one of the most common distressing disorders experienced by people of all age groups characterized by sudden or gradual decline in hair density from the head and other bodily parts. Earlier a high percentage of individuals used to experience hair loss by the age of fifty. However, recently due to lifestyle changes and other factors, many start to see the first sign of hair loss in their adolescence. This widespread nature of hair loss is caused by several factors, which vary among individuals and could be temporary or longlasting. Factors associated with sudden hair loss are illness, medications, dietary habits or childbirth, while gradual hair loss is usually associated with severe distress, workload and depression. The pathophysiological factors involved in hair loss are genetic disorders, endocrine abnormalities, drug intake, nutritional deficiencies, fungal infections and auto-immune disorders ${ }^{1}$. Most people are unaware that hormonal imbalance and iron deficiency are the most common causes of hair loss ${ }^{2,3}$. However, the extent to which these contribute to hair loss is still unclear. Exposure to increasing levels of air pollution, including particulate matter, dust, smoke, sulphur dioxide, nitrogen dioxide, ammonia and polycyclic aromatic hydrocarbons (PAHs) causes 'sensitive scalp

*For correspondence. (e-mail: rakhi.guptazd@gmail.com) syndrome' leading to hair loss ${ }^{4}$. Stress caused by excessive use of hair dryers, hair dyes, hot curlers, hairstraightening products, and chemical-laden cosmetics causes decline in the general health of hair (brittle, dry and thin hair) and ultimately hair loss ${ }^{5}$.

Among the various internal and external factors contributing to hair loss, the quality of water used for hair washing is important in determining the degree of hair loss. Long-term use of water having high levels of positively charged minerals like magnesium, silica, iron and calcium weakens the hair follicles, roots and shafts, leading to dryness, thinning and hair loss ${ }^{6}$.

Therefore, it is important to study the various factors associated with hair loss at regular intervals and generate awareness, as this problem is affecting a high percentage of individuals across the globe. Thus, the present study was undertaken to assess the same from different regions of Delhi and the National Capital Region (NCR) of India using questionnaire-based survey.

The study was conducted with $380(70 \%$ female, $30 \%$ male) randomly selected subjects belonging to different age groups (10-80 years), residing in Delhi and NCR during June to September 2018. Thirteen samples were excluded from the further study who answered the first question negative and the final study was conducted with 367 samples. All the participants were assured of confidentiality. Only willing participants were included in the study after receiving a written consent.

A uniform questionnaire was designed with 34 closeended questions for obtaining information about the occupational status, lifestyle stress, dietary habits, general health, hormonal level and various other factors which directly or indirectly contribute to hair loss among the subjects. The level of awareness with respect to hair loss and its causes was also determined through the study.

Water samples (tap water/groundwater) used for hair washing were collected for measuring total dissolved solids (TDS) level using a TDS metre.

Data collected were compiled, and analysed using percentage statistics. Among the 380 subjects surveyed, $96.58 \%(n=367)$ showed high prevalence of hair loss irrespective of their place of residence, gender and occupation (Table 1). Data collected showed that subjects residing in Faridabad and Gurugram experienced marginally low percentage of hair loss $(87.96 \% \pm$ $5.815 \%, n=108)$ compared to those residing in Delhi $(100 \%, n=207)$ and Noida and Ghaziabad (100\%, $n=65)$. It was observed that compared to non-working subjects $(94.88 \% \pm 2.80 \%, n=241)$, the percentage of working subjects (job or business) experiencing hair loss was high $(100, n=126)$. Further, maximum number of subjects experienced first signs of hair loss at an early age, viz. $10-20$ years $(35.69 \%, n=131)$ and $20-30$ years $(48.77 \%, n=179)$.

Among the 367 subjects, a high percentage (67.58, $n=248$ ) was suffering from gradual hair loss (Table 2). 


\section{RESEARCH COMMUNICATIONS}

Table 1. Socio-demographic conditions and their association with hair loss (figures in parentheses indicate percentage)

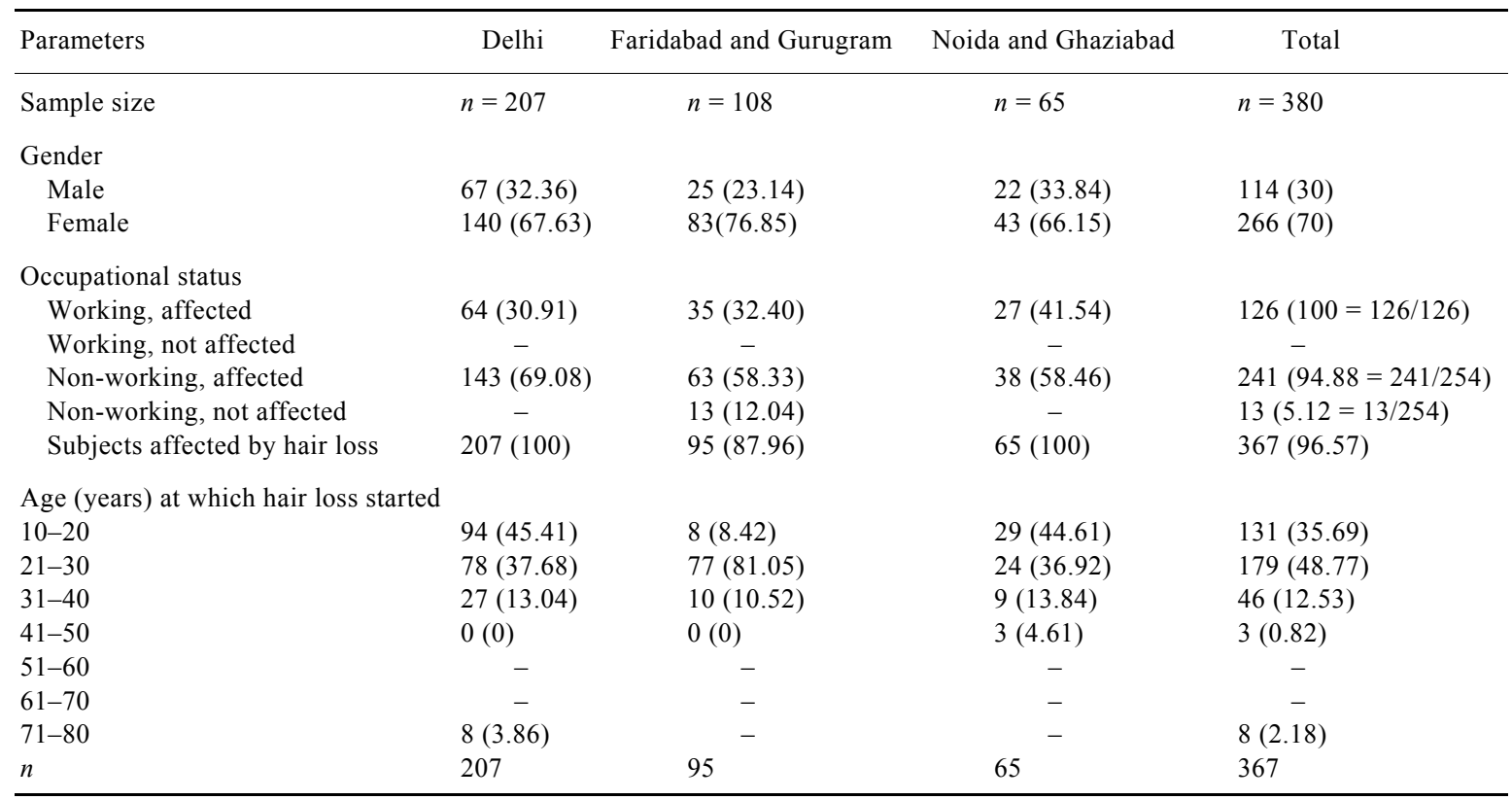

Table 2. Pattern of hair loss (figures in parentheses indicate percentage)

\begin{tabular}{|c|c|c|c|c|}
\hline Parameters & $\begin{array}{c}\text { Delhi } \\
(n=207)\end{array}$ & $\begin{array}{c}\text { Faridabad and } \\
\text { Gurugram }(n=95)\end{array}$ & $\begin{array}{c}\text { Noida and } \\
\text { Ghaziabad }(n=65)\end{array}$ & $\begin{array}{c}\text { Total } \\
(n=367)\end{array}$ \\
\hline \multicolumn{5}{|l|}{ How rapid was hair loss at the start? } \\
\hline Gradual & $134(64.73)$ & $78(82.10)$ & $36(55.38)$ & $248(67.58)$ \\
\hline Sudden & $59(28.50)$ & $17(17.89)$ & $29(44.61)$ & $105(28.61)$ \\
\hline Do not know & $14(6.76)$ & - & - & $14(3.81)$ \\
\hline Breaking off & $103(49.75)$ & $24(25.26)$ & $35(53.84)$ & $162(44.14)$ \\
\hline Coming out with root attached & $103(49.75)$ & $71(74.73)$ & $30(46.15)$ & $204(55.59)$ \\
\hline Both & $1(0.48)$ & 0 & 0 & $1(0.29)$ \\
\hline \multicolumn{5}{|c|}{ Does the problem get aggravated in specific weather } \\
\hline Yes & $97(46.85)$ & $49(51.57)$ & $34(52.30)$ & $180(49.05)$ \\
\hline No & $104(50.24)$ & $46(48.42)$ & $31(47.69)$ & $181(49.32)$ \\
\hline Do not know & $6(2.89)$ & $0(0)$ & $0(0)$ & $6(1.63)$ \\
\hline
\end{tabular}

More than half $(55.58 \%, n=204)$ of the subjects reported that their hair came out with root attached, a condition detrimental to the regrowth of new hair. However, it was reported that in almost half $(49.32 \%, n=181)$ of the subjects, the severity of hair loss was not associated with changing weather and remained persistent throughout the year.

It is indispensable to underline the role of chemical treatment in terms of shampoo used and proper diet with respect to hair loss. With this objective, subjects were questioned to check their awareness level and importance of appropriate shampoo depending on hair type and its impact on hair loss. It was found that only $46.86 \%$ $(n=172)$ participants changed shampoo after experiencing hair loss and a significant number among them $(50 \%$, $n=86$ ) was relieved (Table 3 ). An overwhelming majority
$(70.57 \%, n=259)$ of subjects surveyed had never chemically coloured their hair. Similarly, 75.74\% $(n=278)$ surveyed subjects had never applied heat treatment to their hair (Table 4).

With regard to proper diet and nutrition, majority of participants $(93.73 \%, n=344)$ were not following any particular diet and only $5.99 \%(n=22)$ of the participants began to take special diet in terms of higher protein intake (pulses and meat) and green vegetables for relief. When they were cross-questioned regarding decline in hair loss after intake of special diet, only $31.81 \%(n=7)$ gave positive response (Table 3 ).

When participants were asked about physical appearance of hair, $32.42 \%(n=119)$ responded that they had thin and rough hair while $22.61 \%$ had rough and thick hair $(n=83)$ (Table 5). To interpret the impact of water 


\section{RESEARCH COMMUNICATIONS}

Table 3. Awareness regarding role of personal care and diet in relation to hair loss (figures in parentheses indicate percentage)

\begin{tabular}{|c|c|c|c|c|}
\hline Parameters & Delhi & Faridabad and Gurugram & Noida and Ghaziabad & Total \\
\hline \multicolumn{5}{|c|}{ Have you changed shampoo after the start of hair loss? } \\
\hline Yes & $84(40.57)$ & $57(60)$ & $31(47.69)$ & $172(46.86)$ \\
\hline No & $123(59.42)$ & $38(40)$ & $34(52.30)$ & $195(53.13)$ \\
\hline$n$ & 207 & 95 & 65 & 367 \\
\hline \multicolumn{5}{|c|}{ If yes, did it help control hair loss? } \\
\hline Yes & $61(72.61)$ & $18(31.57)$ & $7(22.58)$ & $86(50)$ \\
\hline No & $23(27.38)$ & $39(68.42)$ & $24(77.41)$ & $86(50)$ \\
\hline$n$ & 84 & 57 & 31 & 172 \\
\hline \multicolumn{5}{|c|}{ Have you been on a diet before the start of hair loss? } \\
\hline Yes & $16(7.72)$ & $4(4.21)$ & $3(4.61)$ & $23(6.27)$ \\
\hline No & $191(92.27)$ & $91(95.78)$ & $62(95.38)$ & $344(93.73)$ \\
\hline$n$ & 207 & 95 & 65 & 367 \\
\hline \multicolumn{5}{|c|}{ Have you started any special diet to control hair loss? } \\
\hline Yes & $13(6.28)$ & $4(4.21)$ & $5(7.69)$ & $22(6)$ \\
\hline No & $194(93.71)$ & $91(95.78)$ & $60(92.30)$ & $345(94)$ \\
\hline$n$ & 207 & 95 & 65 & 367 \\
\hline \multicolumn{5}{|c|}{ If yes, did it help control hair loss? } \\
\hline Yes & $4(30.76)$ & $2(50)$ & $1(20)$ & $7(31.81)$ \\
\hline No & $8(61.53)$ & $2(50)$ & $4(80)$ & $14(63.63)$ \\
\hline No idea & $1(7.69)$ & - & - & $1(4.54)$ \\
\hline$n$ & 13 & 4 & 5 & 22 \\
\hline
\end{tabular}

Table 4. Awareness regarding various adornment factors on hair (figures in parentheses indicate percentage)

\begin{tabular}{|c|c|c|c|c|}
\hline Parameters & $\begin{array}{c}\text { Delhi } \\
(n=207)\end{array}$ & $\begin{array}{l}\text { Faridabad and Gurugram } \\
\qquad(n=95)\end{array}$ & $\begin{array}{l}\text { Noida and Ghaziabad } \\
\qquad(n=65)\end{array}$ & $\begin{array}{c}\text { Total } \\
(n=367)\end{array}$ \\
\hline \multicolumn{5}{|c|}{ How often is your hair chemically treated for colouring/straightening? } \\
\hline Never & $143(69.08)$ & $61(64.21)$ & $55(84.61)$ & $259(70.57)$ \\
\hline Weekly & $6(2.89)$ & $6(6.31)$ & $7(10.76)$ & $19(5.18)$ \\
\hline Monthly & $58(28.01)$ & $28(29.47)$ & $3(4.61)$ & $89(24.25)$ \\
\hline \multicolumn{5}{|c|}{ How often is your hair heat treated for curling/blow drying/straightening? } \\
\hline Never & $155(74.87)$ & $73(76.84)$ & $51(78.46)$ & $278(75.74)$ \\
\hline Weekly & $13(6.28)$ & $8(8.42)$ & $5(7.69)$ & $26(7.08)$ \\
\hline Monthly & $39(18.84)$ & $14(14.73)$ & $9(13.84)$ & $62(16.89)$ \\
\hline
\end{tabular}

quality used for hair washing the subjects were questioned about the type of water used. It was found that a majority of subjects used tap water for hair washing $(92.64 \%, n=340)$. Besides the fact that a high percentage of subjects (85.01, $n=312$ ) were aware about of the role of water in hair loss, only one subject attempted to switch the water used for hair washing. Further, TDS level of water was measured and it was concluded that 267 samples had TDS level below $500 \mathrm{ppm}$ while for 71 samples it was higher than $900 \mathrm{ppm}$. According to the US Environmental Protection Agency (EPA), the permissible limit for TDS is 500 ppm.

Hair loss is associated with various factors, and abnormality or disturbance in any of these factors causes the disorder. It is important to assess the awareness level of studied subjects regarding these factors, as a cure is possible only when an underlying factor is known (Table 6). With this aim, subjects were questioned whether their iron and hormonal levels had been checked. Only $22.34 \%$ $(n=82)$ and $10.08 \%(n=37)$ subjects opted for quantitative analysis of iron and hormonal levels in the blood respectively. It was observed that subjects from Faridabad and Gurugram were more cautious about hair loss and opted for laboratory test. It was analysed that a significantly low $(6.81 \%, n=25)$ number of subjects were aware about the fact that hair loss could be a result of genetic factors.

It is interesting to note that all 367 subjects had some problem with the scalp, as $69.75 \%(n=256)$ participants were suffering with clinical conditions like burning or itching of the scalp, while the remaining $39.50 \%(n=145)$ of the subjects had dandruff or flakes on the scalp (Table $7)$. Only $14.44 \%(n=53)$ of the subjects were concerned about hair loss and consulted a medical practitioner.

Hair loss affects both males and females, leading to decline in hair density and in some cases, baldness. 
RESEARCH COMMUNICATIONS

Table 5. Physical appearance of hair and its co-relation with hardness of water (figures in parentheses indicate percentage)

\begin{tabular}{|c|c|c|c|c|}
\hline Parameters & $\begin{array}{c}\text { Delhi } \\
(n=208)\end{array}$ & $\begin{array}{l}\text { Faridabad and Gurugram } \\
\qquad(n=95)\end{array}$ & $\begin{array}{l}\text { Noida and Ghaziabad } \\
\qquad(n=65)\end{array}$ & $\begin{array}{c}\text { Total } \\
(n=367)\end{array}$ \\
\hline \multicolumn{5}{|l|}{ Texture of hair } \\
\hline Thick & $7(3.38)$ & $4(4.21)$ & $4(6.15)$ & $15(4.08)$ \\
\hline Rough and thin & $62(29.95)$ & $28(29.47)$ & $29(44.61)$ & $119(32.42)$ \\
\hline Silk and thick & $35(16.90)$ & $33(34.73)$ & $1(1.53)$ & $69(18.80)$ \\
\hline Rough and thick & $53(25.60)$ & $9(9.47)$ & $21(32.30)$ & $83(22.61)$ \\
\hline \multicolumn{5}{|c|}{ What is the source of water for hair-washing? } \\
\hline Tap water & $189(91.30)$ & $93(97.89)$ & $58(89.23)$ & $340(92.64)$ \\
\hline Groundwater & $18(8.69)$ & $2(2.10)$ & $7(10.76)$ & $27(7.36)$ \\
\hline \multicolumn{5}{|c|}{ Do you think that hardness of water affects hair loss directly? } \\
\hline Yes & $181(87.43)$ & $70(73.68)$ & $61(93.84)$ & $312(85.01)$ \\
\hline No & $26(12.56)$ & $25(26.31)$ & $4(6.15)$ & $55(14.99)$ \\
\hline Yes & $0(0)$ & $1(1.06)$ & $0(0)$ & 1 \\
\hline No & $207(100)$ & $94(98.94)$ & $65(100)$ & 366 \\
\hline \multicolumn{5}{|l|}{ If yes, did it help? } \\
\hline Yes & 0 & 0 & 0 & 0 \\
\hline No & 0 & $1(100)$ & 0 & 0 \\
\hline \multicolumn{5}{|c|}{ Total dissolved solids level of water used for hair washing } \\
\hline Below 100 & $41(19.80)$ & $12(12.63)$ & $0(0)$ & $53(14.44)$ \\
\hline $100-300$ & $120(57.97)$ & $44(46.31)$ & $0(0)$ & 164 (44.69) \\
\hline $300-500$ & $32(15.45)$ & $17(17.89)$ & $1(1.53)$ & $50(13.62)$ \\
\hline $500-700$ & $7(3.38)$ & $16(16.84)$ & $0(0)$ & $23(6.27)$ \\
\hline $700-900$ & $1(0.48)$ & $0(0)$ & $5(7.69)$ & $6(1.63)$ \\
\hline Above 900 & $6(2.89)$ & $6(6.31)$ & $59(90.76)$ & $71(19.35)$ \\
\hline
\end{tabular}

Table 6. Awareness level of subjects with respect to various causative factors of hair loss (figures in parentheses indicate percentage)

\begin{tabular}{|c|c|c|c|c|}
\hline Parameters & Delhi & $\begin{array}{c}\text { Faridabad and } \\
\text { Gurugram }\end{array}$ & $\begin{array}{l}\text { Noida and } \\
\text { Ghaziabad }\end{array}$ & Total \\
\hline \multicolumn{5}{|c|}{ Have you ever checked your iron content? } \\
\hline Yes & $37(17.87)$ & $40(42.10)$ & $5(7.69)$ & $82(22.34)$ \\
\hline No & $170(82.12)$ & $55(57.89)$ & $60(92.30)$ & $285(77.66)$ \\
\hline$n$ & 207 & 95 & 65 & 367 \\
\hline \multicolumn{5}{|c|}{ If yes, whether the iron levels were within range? } \\
\hline Yes & $23(62.16)$ & $32(80)$ & $2(40)$ & $57(69.51)$ \\
\hline No & $14(37.83)$ & $8(20)$ & $3(60)$ & $25(30.49)$ \\
\hline$n$ & 37 & 40 & 5 & 82 \\
\hline \multicolumn{5}{|c|}{ Have your hormone levels ever been checked to evaluate hair loss? } \\
\hline Yes & $17(8.21)$ & $15(15.78)$ & $5(7.69)$ & $37(10.08)$ \\
\hline No & $190(91.78)$ & $80(84.21)$ & $60(92.30)$ & $330(89.92)$ \\
\hline$n$ & 207 & 95 & 65 & 367 \\
\hline \multicolumn{5}{|c|}{ If yes, whether the hormone levels were within range? } \\
\hline Yes & $10(58.82)$ & $10(66.66)$ & $2(40)$ & $22(59.45)$ \\
\hline No & $7(41.17)$ & $5(33.33)$ & $3(60)$ & $15(40.54)$ \\
\hline$n$ & 17 & 15 & 5 & 37 \\
\hline \multicolumn{5}{|c|}{ Do you think that it is a genetic disorder? } \\
\hline Yes & $17(8.21)$ & $4(4.21)$ & $4(6.15)$ & $25(6.81)$ \\
\hline No & $190(91.78)$ & $91(95.78)$ & $61(93.84)$ & $342(93.19)$ \\
\hline$n$ & 207 & 95 & 65 & 367 \\
\hline \multicolumn{5}{|c|}{ If yes, from whom have you probably inherited it? } \\
\hline Father & $12(70.58)$ & $3(75)$ & $1(25)$ & $16(64)$ \\
\hline Mother & $5(29.41)$ & $0(0)$ & $2(50)$ & $7(28)$ \\
\hline Both & 0 & $1(25)$ & $1(25)$ & $2(8)$ \\
\hline$n$ & 17 & 4 & 4 & 25 \\
\hline
\end{tabular}


Table 7. Associated clinical condition and medication for hair loss (figures in parentheses indicate percentage)

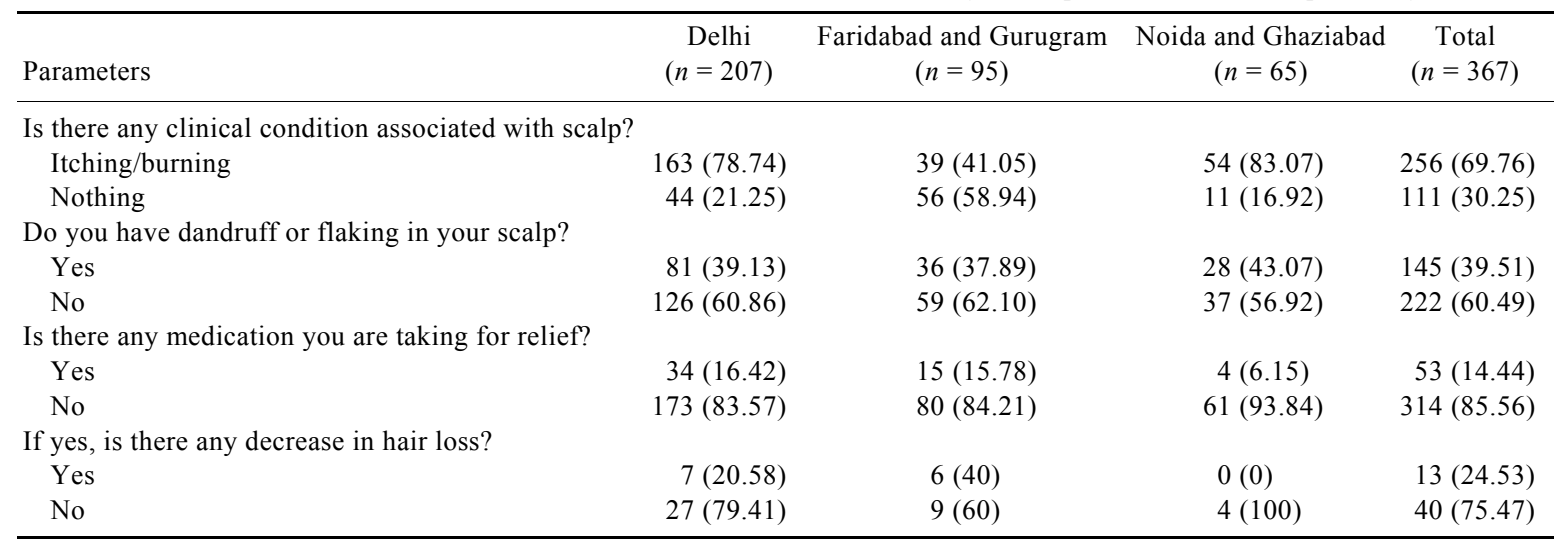

Various factors causing hair loss are both internal (from enzymes to hormones) as well as external ${ }^{7}$. Earlier hair loss was considered to be an age-related phenomenon. However, at present a high percentage of subjects are experiencing hair loss at an early age between 10 and 20 years $(35.69 \%, n=131)$ and 20 and 30 years $(48.77 \%$, $n=179$ ). This depicts that hair loss is related to other factors as well. Keeping this in view, further questions were framed to decipher and analyse the various factors contributing to early start of hair loss. It has been reported that there is high prevalence of abrupt and short-term hairloss during extreme weather conditions, but gradual hair loss $(49.05 \%, n=180)$ throughout the year $(49.32 \%, n=181)$ indicates that it is not likely to be a physiological cycle, but a result of external or internal disturbances. Frequent use of shampoos containing synthetic ingredients not only make the hair dry and dull, but also has other side effects in terms of increased hair fall because of the presence of alkanolamides used as a surfactant. It is interesting to note that the maximum number of participants who got relief after changing their shampoo $(n=61)$ were from Delhi. In cities, hardness of water is the major cause of hair loss. It contains high amounts of magnesium, silica and calcium, which leads to breakage, dryness and thinning of hair. Hard water also results in dandruff and destroys hair follicles and is therefore detrimental to the regrowth of new hair ${ }^{6}$. In the present study, the impact of high dissolved solids on hair loss could not be ascertained as only 100 subjects $(27.25 \%)$ were using water with TDS level above $500 \mathrm{ppm}$.

Table 6 shows that majority of subjects were unaware of the role of special diet, iron content, hormonal levels and genetic factors with respect to hair loss. It has been reported that only $6 \%$ of the subjects were aware about the role of special diet and proper nutrition. Iron deficiency is the world's most common nutritional deficiency and is a well-known cause of hair $\operatorname{loss}^{8}$. It has been studied that iron works as a cofactor for ribonucleotide reductase, the rate-limiting enzyme for DNA synthesis. Hair follicles are one of the most rapidly dividing cells in our body and ribonucleotide reductase helps in the divi- sion and growth of hair follicles ${ }^{2}$. In addition, multiple genes have been identified in human hair follicles regulated by iron ${ }^{9,10}$.

In males and females, hair loss is androgen- and estrogen-dependent respectively ${ }^{3,11}$. Dihydrotestosterone (DHT), a more potent form of testosterone in males is synthesized from testosterone by a specific enzyme, 5-alpha reductase. While both testosterone and DHT are known to have a weakening effect on hair follicles, there appears to be something unique about the conversion process of testosterone to DTH that is related to hair thinning. This is why some drugs that are marketed for hair loss block the conversion of testosterone to DHT. In females, hair loss is one of the most common symptom of polycystic ovary syndrome (PCOS). It has been reported that most of the women who have PCOS also suffer from with androgenic alopecia ${ }^{12,13}$. The data collected in the present study depict a low level of awareness among the subjects regarding hormonal level as only 37 subjects had their hormonal levels checked. Along with nutrition and hormonal level, genetic factor is one of the most important internal factors contributing to hair loss. It has been reported that the genetic machinery controls the metabolism of hormones and active substances required for hair growth and proliferation of hair follicles. However, only $6.81 \%(n=25)$ subjects considered this as a plausible cause for hair loss.

According to statistical analysis of data, $69.76 \%$ subjects reported itching/burning of scalp, which could be identified as 'sensitive scalp syndrome' resulting from exposure to increasing levels of air pollution, including particulate matter, dust, smoke, nickel, lead, arsenic, sulphur dioxide, nitrogen dioxide, ammonia and PAHs which settle on the scalp and hair. This could be the reason why non-working people are also experiencing hair loss, as the indoor environment contains volatile organic compounds released from various sources which deposit on the scalp. The pollutants transepidermally migrate to the dermis, thus leading to oxidative stress and hair loss. With such a high prevalence of hair loss, only $14.44 \%$ subjects consulted a medical practitioner. 
Thus, the present study shows that the younger population is most affected by hair loss. Lifestyle related stress and pollution are the major factors responsible for hair loss, along with hardness of water which leads to scalprelated problems like dandruff and flaking. Majority of the population was unaware of the contribution of special diet, iron content, hormonal levels and genetic features to hair loss. It is imperative to generate awareness among the population regarding the causative factors, as persistent and long-term hair loss is an indicator of some physiological or environmental disturbances.

Conflict of interest: The authors declare no conflict of interest.

1. Naveed, S., Hmeed, A., Ilyas, H., Saleem, A., Kanwal, H., Ali, E. and Iqbal, R., Prevalence and consequences of hair fall, survey based study in Karachi. Mintage J. Pharm. Med. Sci., 2015, 1(suppl 1), 11-20.

2. Moeinvaziri, M., Mansoori, P., Holakooee, K., Naraghi, Z. S. and Abbasi, A., Iron status in diffuse telogen hair loss among women. Acta Dermatovenerol. Croat., 2009, 17(4), 279-284.

3. Urysiak-Czubatka, I., Kmiec, M. L. and Broniarczyk-Dyla, G., Assessment of the usefulness of dihydrotestosterone in the diagnostics of patients with androgenetic alopecia. Postepy Dermatol. Alergol., 2014, 31(4), 207-215; doi:10.5114/pdia.2014.40925.

4. Godse, K. and Zawar, V., Sensitive scale. Int. J. Triology., 2012, 4(2), 102-104.

5. Nayak, B. S., Ann, C. Y., Azhar, A. B., Su Ling, E. C., Yen, W. H. and Aithal, P. A., A study on scalp hair health and hair care practices among Malaysian medical students. Int. J. Trichol., 2017, 9(2), 58-62; doi:10.4103/ijt.ijt_76_16. PMID:28839388.

6. Srinivasan, G., Rangachari, C., Mathew, A. C. and Duraiswami, D., Effects of hard water on hair. Int. J. Trichol., 2013, 5(3), 137139; doi:10.4103/0974-7753.125609; https://www.ncbi.nlm. nih.gov/pmc/articles/PMC3927171/

7. Pingale, P. L., Daude, R. B., Ghegade, R. Y. and Amrutkar, S. V., A review on alopecia and its remedies. Int. J. Pharmacol. Pharmaceut. Sci., 2014, 2(3), 45-52.

8. Guo, E. L. and Katta, R., Diet and hair loss: effects of nutrien deficiency and supplement use. Dermatol. Pract. Concept., 2017, 7(1), 1; doi:http://dx.doi.org/10.5826/dpc.0701a01.

9. Ohyama, M., Terunuma, A. and Tock, C. L., Characterization and isolation of stem cell-enriched human hair follicle bulge cells. J. Clin. Invest., 2006, 116(1), 249-260.

10. St Pierre, S. A., Vercellotti, G. M., Donovan, J. C. and Hordinsky, M. K., Iron deficiency and diffuse nonscarring scalp alopecia in women: more pieces to the puzzle. J. Am. Acad. Dermatol., 2010, 63(6), 1070-1076

11. Stevenson, S. and Thornton, J., Effect of estrogens on skin aging and the potential role of SERMs. Clin. Interv. Aging, 2007, 2(3), 283-297.

12. Brough, K. R. and Torgerson, R. R., Hormonal therapy in female pattern hair loss. Int. J. Women's Dermatol., 2017, 3, 53-57.

13. Cela, E. et al., Prevalence of polycystic ovaries in women with androgenic alopecia. Eur. J. Endocrinol., 2003, 149, 439-442.

ACKNOWLEDGEMENT. We thank the Principal, Maitreyi College, Delhi for support and encouragement.

Received 19 September 2019; accepted 31 October 2019

doi: $10.18520 / \mathrm{cs} / \mathrm{v} 118 / \mathrm{i} 5 / 786-791$

\section{A comparative study of physical properties of yarns and fabrics produced from fresh and recycled fibres}

\author{
Neelam Saini*, Saroj Yadav and Neelam M. Rose \\ Department of Textile and Apparel Designing, I.C. College of Home \\ Science, CCS Haryana Agricultural University, Hisar 125 024, India
}

Recycling is the process of producing new products with additional qualities from old materials which are no more in use. Furthermore, the decreasing natural resources forced researchers to produce new synthetic products from waste products using new technologies. This study compares the physical properties of yarns and fabrics produced using blends of fresh and recycled fibres/fabrics of wool, acrylic and polyester; these were used to manufacture fabrics through weaving technique. Physical properties of yarns, i.e. tensile strength, twist per inch of fabrics, i.e. tensile strength, elongation and bending length were measured and statistically analysed. The results showed that the physical properties of recycled yarns and fabrics were comparable to control/fresh yarns and fabrics. The strength of recycled yarns and fabrics was little different than control products. Thus, recycled yarns and fabrics can be used for the production of woollen apparels with suitable properties like smooth texture, appeal, etc.

Keywords: Fabrics, physical properties, recycling, yarns.

INDIA is the second largest producer of textiles and garments in the world and according to a report by Technopak Advisors the Indian textiles and apparel industry is expected to grow to about US\$ 223 billion by 2021 . The Indian textile industry is the oldest industry providing employment and earning foreign exchange for the country (http://info.shine.com/industry/textiles/17.html). As consumers are becoming more fashion-oriented, every year millions of garments are discarded because they are either worn out, damaged, outgrown or gone out of fashion. As a result, several textile and clothing items are disposed-off into the trash and end up in municipal landfills. Throwing away clothes is not only wasteful but also harmful for society and creates pollution problems.

For proper waste management and to generate minimum amount of waste, the waste hierarchy has taken many forms over the past decade; 'Reduce, Reuse and Recycle' are the three Rs in the waste hierarchy. Reduce is design for minimum use of energy, minimize or eliminate waste material. Reuse refers to the use an item more than once without reprocessing, which saves time, money,

*For correspondence. (e-mail: sainineelam004@gmail.com) 